Acta vet. scand. 1987, 28, 121-123.

Brief Communication

\title{
Haemoglobin Types of Old Norwegian Short Tail Land Race Sheep
}

Thirty years have passed since it was shown that sheep have two types of haemoglobin $(\mathrm{Hb}), \mathrm{A}$ and B. Since then a large number of studies have been undertaken; gene frequencies, relations and origins of breeds, biochemistry, correlations with diseases, to mention the most important fields for which these 2 haemoglobins have been utilized. A few years ago, in a number of studies, Vestri and coworkers (Vestri et al. 1983) using chromatographic and biochemical methods together with isoelectric focusing showed that in Italian sheep additional $\mathrm{Hb}$ types occurred. These new types are caused by substitutions in the alpha chains, in contrast to the A and B difference which is caused by 7 amino acid substitutions in the beta chain (Huisman et al. 1965). Vestri et al (1983) also proved that the alpha chains in sheep, as in man, horse and goat among others, are controlled by 2 closely linked alpha globin genes.

At the western coast of Norway, on the island Selbjørn, there is a total of some 400 sheep. They live outdoors all the year and are only assembled for shearing in June and for selection of animals to be slaughtered in September. They are owned by the local farmers but not individually marked, only with the ear mark of their owners. These sheep are assumed to be little influenced by other sheep breeds and therefore probably represent the original land race sheep of Norway. They are small sheep but with great variation in colours. It was found of interest to investigate the $\mathrm{Hb}$ types of these sheep using isoelectric focusing in polyacrylamide gels, with Pharmalyte and Immobiline, both of pH range 6.7-7.7 (Braend et al. 1987).

In Fig. 1 selected $\mathrm{Hb}$ phenotypes of the Selbjørn sheep are shown. Nos. 1 and 12 are one band types, homozygous for B and A respectively. Since, however, an $\mathrm{Hb}$ molecule is composed of 2 alpha and 2 beta chains, it is genetically controlled by 2 independent genetic systems, 2 closely linked genes for the alpha chains (Vestri et al. 1983) and a beta gene for the beta chain. In nos. 1 and 12, however, the 2 alpha globin genes produce identical alpha chains, both with leucine in position 113 (Vestri et al. 1983). Samples nos. 3 and 5 have also the A and $\mathrm{B}$ types but an additional, weaker, $\mathrm{Hb}$ band. This is assumed to be the $\mathrm{Hb}$ molecule which Vestri et al. found to have an alpha chain with histidine at position 113 instead of leucine. This causes a difference in isoelectric point (PI), which is detectable by isoelectric focusing. The two closely linked genes controlling these two alpha chains of the $\mathrm{Hb}$ molecule, one with leucine the other with histidine, is called a haplotype and can be written as $\alpha^{\mathrm{Le}} \alpha^{\mathrm{Hi}}$. In sheep homozygous for this haplotype the ratio of the anodal to the cathodal band is 1.8 to 1 (Vestri et al. 1983). In heterozygotes is was found to be about 4 to 1 . In our study we could by eye see differences in band ratios, easily in nos. 3 and 5 , but others were so weak that they are not seen clearly on the photograph. The weak ones $(4,6,7)$ could be heterozygous for the 2 haplotypes $\alpha^{\mathrm{Le}} \alpha^{\mathrm{Hi}}$ and $\alpha^{\text {Le }}$, which also could be written as $\alpha^{\text {Le }}$ $\alpha^{\text {Le }}$. A third type of alpha chain is the result 


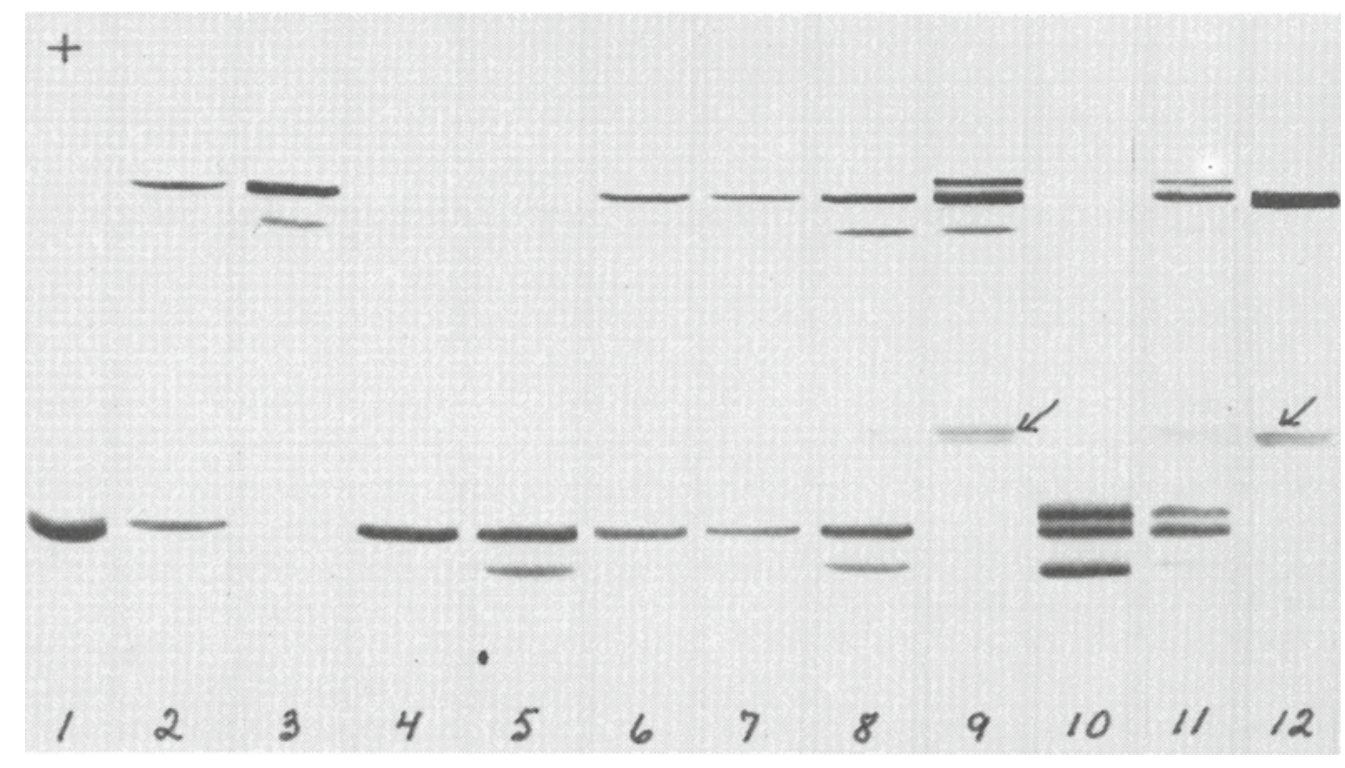

Figure 1. Photograph of portion of an Immobiline gel, $\mathrm{pH}$ range 6.7-7.7, showing selected $\mathrm{Hb}$ phenotypes. No. 1: $\mathrm{B} \alpha^{\mathrm{Le}}$, no. 2: $\mathrm{AB} \alpha^{\mathrm{Le}}$, no. 3: $\mathrm{A} \alpha^{\mathrm{Le}} \alpha^{\mathrm{Hi}}$, no. $4: \mathrm{B} \alpha^{\mathrm{Le}} \alpha^{\mathrm{Hi}}$ ( $\alpha^{\mathrm{Hi}}$ weak), no. 5: $\mathrm{B} \alpha^{\mathrm{Le}} \alpha^{\mathrm{Hi}}$, nos. 6 \& 7: $\mathrm{AB} \alpha^{\mathrm{Le}} \alpha^{\mathrm{Hi}}$ ( $\alpha^{\mathrm{Hi}}$ weak), no. 8: $\mathrm{AB} \alpha^{\mathrm{Le}} \alpha^{\mathrm{Hi}}$, no. 9: $\mathrm{A} \alpha^{\mathrm{AlLe}} \alpha^{\mathrm{Hi}} \alpha^{\mathrm{Le}}$, no. 10: $\mathrm{B} \alpha^{\mathrm{AlLe}} \alpha^{\mathrm{Hi}} \alpha^{\mathrm{Le}} \alpha^{\mathrm{Hi}}$, no. 11: $\mathrm{AB} \alpha^{\mathrm{AlLe}} \alpha^{\mathrm{Hi}} \alpha^{\mathrm{Le}}$ ( $\alpha^{\mathrm{Hi}}$ weak), no. 12: $\mathrm{A} \alpha^{\mathrm{Le}}$. Extra bands which are assumed to be metHb are marked with arrows.

of a substitution at position no. 8 in the alpha chain having leucine at 113 , but with its gene being linked to the $\alpha^{\mathrm{Hi}}$ gene (Vestri et al. 1983). The replacement of serine by alanine at position 8 causes a difference in PI. Judged by published photographs of $\mathrm{Hb}$ types in Italian sheep it is assumed that the third alpha chain occurring in nos 9,10 and 11 is the same as that found in Italy.

In Table 1 observed phenotypes are presented. Since it is not known whether some sheep may have been sampled twice, the results are reported separately for the 41 sheep bled in june and the 42 bled in September. According to theory 18 phenotypes are possible, when we exclude recombinants. Adult, normal sheep may have 1, 2, 3, 4 or $6 \mathrm{Hb}$ molecules. In Table 1 formulas for 15 phenotypes are given, since we could not with certainty differentiate between phenotypes homozygous for the $\alpha^{\mathrm{Le}} \alpha^{\mathrm{Hi}}$ haplotype and those being heterozygous, with $\alpha^{\text {Le }}$ as the other haplotype. Differentiation based on band ratios was, however, done for the various haplotype combinations having alanine at position no. 8 , even though this was judged by eye and therefore, not as exact as would have been desirable. Twelve different phenotypes were found (Table 1). Most remarkable is the great $\mathrm{Hb}$ variation and the high frequency of $\mathrm{Hb} \mathrm{B}$. This is in contrast to the frequency of 1 to $4 \%$ in the common Short Tail Land Race sheep in Norway (Efremov \& Braend 1965, Braend unpublished). The occurrence of the $\alpha^{\text {AlLe }} \alpha^{\mathrm{Hi}}$ haplotype at a frequency as high as 0.17 is also of interest since this type has so far not been found in other Norwegian sheep (Braend unpublished). 
Table 1. Haemoglobin types in Old Norwegian Short Tail Land Race sheep.

\begin{tabular}{lccc}
\hline & $\mathrm{A} \alpha^{\mathrm{Le}}$ & $\mathrm{AB} \alpha^{\mathrm{Le}}$ & $\mathrm{B} \alpha^{\mathrm{Le}}$ \\
June & 1 & 2 & 2 \\
Sept & $\mathrm{A} \alpha^{\mathrm{Le}} \alpha^{\mathrm{Hi}}$ & 2 & $\mathrm{AB} \alpha^{\mathrm{Le}} \alpha^{\mathrm{Hi}}$ \\
June & 9 & 18 & $\mathrm{~B} \alpha^{\mathrm{Le}} \alpha^{\mathrm{Hi}}$ \\
Sept & 7 & 12 & 5 \\
& $\mathrm{~A} \alpha^{\mathrm{AlLe}} \alpha^{\mathrm{Hi}}$ & $\mathrm{AB} \alpha^{\mathrm{AlLe}} \alpha^{\mathrm{Hi}}$ & $\mathrm{B} \alpha^{\mathrm{AlLe}} \alpha^{\mathrm{Hi}}$ \\
June & & 2 & \\
Sept & & 1 & $\mathrm{~B} \alpha^{\mathrm{AlLe}} \alpha^{\mathrm{Hi}} \alpha^{\mathrm{Le}}$ \\
& $\mathrm{A} \alpha^{\mathrm{AlLe}} \alpha^{\mathrm{Hi}} \alpha^{\mathrm{Le}}$ & $\mathrm{AB} \alpha^{\mathrm{AlLe}} \alpha^{\mathrm{Hi}} \alpha^{\mathrm{Le}}$ & \\
June & 1 & 5 & $\mathrm{~B} \alpha^{\mathrm{AlLe}} \alpha^{\mathrm{Hi}} \alpha^{\mathrm{Le}} \alpha^{\mathrm{Hi}}$ \\
Sept & 1 & 4 & 1 \\
& $\mathrm{~A} \alpha^{\mathrm{AlLe}} \alpha^{\mathrm{Hi}} \alpha^{\mathrm{Le}} \alpha^{\mathrm{Hi}}$ & $\mathrm{AB} \alpha^{\mathrm{AlLe}} \alpha^{\mathrm{Hi}} \alpha^{\mathrm{Le}} \alpha^{\mathrm{Hi}}$ & 2 \\
June & 2 & 1 & 2 \\
Sept & 3 & &
\end{tabular}

Gene frequencies: June, $\mathrm{A}=0.63, \mathrm{~B}=0.37$ Haplotype frequencies: June, $\alpha^{\mathrm{AlLe}} \alpha^{\mathrm{Hi}}=0.17$

Sept, $\mathrm{A}=0.54, \mathrm{~B}=0.46 \quad$ Sept, $\alpha^{\mathrm{AlLe}} \alpha^{\mathrm{Hi}}=0.17$

\section{Acknowledgement}

We are grateful to the sheep owners at Selbjørn for their willingness and help in supplying blood samples.

\section{Braend}

Norwegian College of Veterinary Medicine, Oslo.

\section{$J$. Aursjø and $O$. Austbo}

The Regional Veterinary Laboratory in Bergen.

\section{References}

Braend $M$, Nesse LL, Efremov G: Expression and genetics of caprine haemoglobins. Animal Genetics 1987. In press.
Efremov G, Braend $M$ : Haemoglobins, transferrins and albumins of sheep and goats. Proc. IXth Europ. Conf. Animal Blood Groups. Czech. Acad. Sci. Prague 1965, p. 313-320. Huisman THJ, Reynolds CA, Dozy AM, Wilson $J B$ : The structure of sheep hemoglobins. The amino acid composition of the $\alpha$ and $\beta$ chains of the hemoglobins A, B and C. J. biol. Chem. $1965,240,2455-2460$.

Vestri R, Giordano PC, Bernini LF: Duplication of the hemoglobin $\alpha$ chain in sheep: Characterization of a new $\alpha$ chain variant present in animals possessing the $\alpha^{\text {Leu }}$ and the $\alpha^{\text {His }}$ chains. Biochemical Genetics 1983, 21, 25-35.

(Received December 29, 1986).

Reprints may be requested from: M. Braend, Norwegian College of Veterinary Medicine, P. O. Box 8146, Dep.,N-0033, Oslo 1, Norway. 